\title{
With a little help from my friends: An analysis of the role of social support in digital inequalities
}

\section{Cédric Courtois}

KU Leuven, Belgium

\section{Pieter Verdegem}

Ghent University, Belgium

\begin{abstract}
This article reports an empirical study on the composition and socio-economic background of social support networks and their moderating role in explaining digital inequalities. It conceptually draws upon and empirically reaffirms Van Dijk's multiple access model, acknowledging motivational, material, skill and usage divides, while focussing on the under-researched issue of social support as indispensible source of social learning. Besides a small group of self-reliants, the results indicate a pattern of relatively socially disadvantaged domestic support receivers, characterized by lower digital resources. A second social support pattern points to a relatively socially advantaged non-domestic support receivers (i.e. friends/colleagues), high in digital resources. Drawing upon the concept of homophily in social networks, the results indicate a link between offline and online exclusion, perpetuating digital inequalities.
\end{abstract}

\section{Keywords}

Digital inequalities, multiple access model, social support

\section{Corresponding author:}

Cédric Courtois, School for Mass Communication Research, Parkstraat 45 - box 3603, 3000 Leuven,

Belgium.

Email: cedric.courtois@soc.kuleuven.be 


\section{Introduction}

In today's information society, access and mastery of online resources are indispensible participatory prerequisites. Technological capital, that is, the ability to engage with technologies, is generally considered a substantial part of economic, cultural and social capital (Selwyn, 2004). Still, we must acknowledge persisting inequalities that require systematic inquiry. In this article, we build upon existing models of digital inequalities by considering patterns of social support as key social learning resources.

Whereas initial discussion focussed on the binary issue of individual access (BarzilaiNahon, 2006; Norris, 2001; Van Dijk, 2006; Warschauer, 2003), this debate has gradually shifted to researching gradations in digital inclusion (Livingstone and Helsper, 2007). In 2004, DiMaggio, Hargittai, Celeste and Shafer called to consider multiple divides (or inequalities), extending the discussion on technical means to (a) the autonomy of use, that is, having flexible access whenever desired or needed; (b) inequalities in skills, that is, the core literacies to effectively appropriate online spaces; (c) the variation in use, that is, the diversity of purposes to use the Internet for; (d) and even the availability of social support from more experienced users.

Unfortunately, the position of social support is often overlooked in empirical research. This contribution's objective is to build upon existing models, integrating social support. We first hypothesize direct and indirect effects of access quality, motivation and skills on the diversity of positive outcomes derived from the Internet (cf. 'usage gap') (Hargittai and Hinnant, 2008; Van Dijk and Hacker, 2003). This is further extended with the prediction that these effects are moderated by patterns of social support.

\section{Multiple access divides}

This study's conceptual framework is largely inspired by Van Dijk's $(2005,2006)$ multiple access model. It frames digital equalities as products of a series of divides: motivational, material, skills and usage divides. This theoretical model has an epigenetic and recurrent nature: as new online technologies emerge, preceding divides get re-instated (Peter and Valkenburg, 2006).

Motivational divide. A first hurdle is the motivation to access, brought about by emotional (e.g. technophobia) and rational factors (e.g. no need of technology, want-nots). It entails the recognition and acceptance of the potential benefits offered by using the Internet. The issue of motivation has been repeatedly identified as an important explanatory factor. For example, various studies adopting a socio-cognitive perspective on uses-and-gratifications have found direct explanations of Internet attendance by the outcomes users expect from it (LaRose and Eastin, 2004; LaRose et al., 2001; Peters et al., 2006).

Access divide. When the condition of motivation is met, people are enticed to establish physical access, which might be an obstacle in itself due to its financial cost. Although the debate on the digital divide shifted away from the dichotomy of having a connection or not, it remains a key resource that is prone to variation: not everyone enjoys having access at any place, at any time. Hence, the context of access cannot be dismissed as a decisive factor (Hassani, 2006; Selwyn, 2004). 
Skills divide. Nevertheless, when the necessary infrastructure is comfortably available, a third barrier of skills emerges (Hargittai, 2010; Van Deursen and Van Dijk, 2010). In recent years, the debate on the acquisition and employment of the necessary skills or literacies has gained prominence, often being referred to as the second-level digital divide (Hargittai, 2002; Min, 2010). Hargittai and Hinnant (2008) found that self-reported skill is an important factor in explaining the types of Internet usage people display. Building on Social Cognitive Theory (Bandura, 1986, 1994), Eastin and LaRose (2000) too identified self-efficacy as a crucial factor in Internet use. In a series of studies, Van Deursen and Van Dijk (2010) and Van Deursen et al. (2011) pinpointed Internet skills as composed of multiple, conditional dimensions. More specifically, they distinguish between medium-related skills and content-related skills. The former entail operational skills, that is, the basic skills in handling Internet technology, and formal skills, that is, competencies related to navigating the Internet's hyper structure. The latter set of skills comprises information skills, that is, the literacies to seek information, and strategic skills, which could be considered meta-skills as they envision the attainment goaldirected solutions insofar that they are as optimal and efficient as possible. In recent work, partly due to the increasing and continued prominence of networked online media, communication skills were added to content-related skills (Van Deursen et al., 2014).

Usage divide. The fourth divide refers to differences in usage, the so-called usage gap (Hargittai and Hinnant, 2008; Van Dijk, 2005; Van Dijk and Hacker, 2003). It has been repeatedly demonstrated how differences in socio-demographic and socio-economic background translate into differential uses (Verdegem \& Verhoest, 2009). For example, higher educated users tend to use the Internet more for information and services, whereas lower educated users show a preference for entertainment purposes (Bonfadelli, 2002). Years later, Zillien and Hargittai (2009) too found a robust relation between social status and the capital-enhancing usage, suggesting how already privileged users gain relatively more by their online activities (as well as Hargittai and Hinnant, 2008; Livingstone and Helsper, 2007). Hence, as argued by Van Dijk (2005, 2006), differential usage is the ultimate and therefore focal point in addressing digital inequalities, as it reinforces knowledge gaps, that is, the unequal access and appropriation of valuable information sources, due to a dispersion of resources (Bonfadelli, 2002; Wei and Hindman, 2011).

Towards an operational model. This study's aim is to incorporate social support sources into an operational multiple access model. The model's ultimate criterion is the diversity in positive outcomes, varying between economic, social, political, cultural and health purposes. As such, the emphasis is put on the worthwhileness of the Internet in daily life, rather than merely looking into the amount of use (Helsper, 2012). In fact, prior research has shown that the variety in Internet activities is a critical indicator of digital inequalities (Wei, 2012).

This study's model hypothesizes direct effects of the inequality factors on outcome diversity $(\mathrm{H} 1 \mathrm{a} / \mathrm{b} / \mathrm{c})$, but also indirect relations (Table 1$)$. More specifically, we predict a direct effect of access quality on skills (H2a), as well as a mediation of this effect by motivation $(\mathrm{H} 2 \mathrm{~b})$. Access quality is considered the affording substrate that enables us to develop skills, especially when motivated. Finally, we hypothesize that the direct effects of motivation and skills on diversity are not mediated by usage frequency $(\mathrm{H} 3 \mathrm{a} / \mathrm{b})$. Usage 
Table I. Overview of the study's hypotheses.

\begin{tabular}{|c|c|}
\hline$y$ & \\
\hline $\mathrm{HIa}$ & There is a direct effect of access quality on the diversity in positive outcomes \\
\hline $\mathrm{HIb}$ & There is a direct effect of motivation on the diversity in positive outcomes \\
\hline $\mathrm{HIC}$ & There is a direct effect of skills on the diversity in positive outcomes \\
\hline $\mathrm{H} 2 \mathrm{a}$ & There is a direct effect of access quality on skills \\
\hline $\mathrm{H} 2 \mathrm{~b}$ & The direct effect of access quality on skills is mediated by motivation \\
\hline $\mathrm{H} 3 \mathrm{a}$ & $\begin{array}{l}\text { The direct effect of motivation on the diversity in positive outcomes is not } \\
\text { mediated by usage frequency }\end{array}$ \\
\hline $\mathrm{H} 3 \mathrm{~b}$ & $\begin{array}{l}\text { The direct effect of skills on the diversity in positive outcomes is not mediated by } \\
\text { usage frequency }\end{array}$ \\
\hline $\mathrm{H} 4 \mathrm{a}$ & Social support consists of a substantial proportion of self-reliant, enactive learners \\
\hline $\mathrm{H} 4 \mathrm{~b}$ & $\begin{array}{l}\text { Social support consists of a substantial proportion of vicarious learners, drawing } \\
\text { upon family support }\end{array}$ \\
\hline $\mathrm{H} 4 \mathrm{c}$ & $\begin{array}{l}\text { Social support consists of a substantial proportion of vicarious learners, drawing } \\
\text { upon workplace support }\end{array}$ \\
\hline $\mathrm{H} 5$ & $\begin{array}{l}\text { These differences in social support are explained by socio-demographic variables, } \\
\text { indicating pre-existing social and economic inequalities }\end{array}$ \\
\hline $\mathrm{H} 6$ & $\begin{array}{l}\text { These differences in social support moderate the direct and indirect effects } \\
\text { posited in } \mathrm{HI}-\mathrm{H} 3\end{array}$ \\
\hline
\end{tabular}

frequency is employed as a control variable to assure that the width of positive outcomes is not just a mere function of the amount of time spent online. This would be in line with the findings on the usage gap, pinpointing time spent online not necessarily as efficient in attaining positive outcomes.

\section{Support networks}

The key issue in this study is extending the multiple access model by incorporating social support networks, consisting of familiar people able to incite, guide and support Internet appropriation (Hampton et al., 2011).

Stewart (2007) stresses the value of 'local experts', which he describes as 'individuals who play a key role in the support of ICT adoption and use within a heterogeneous social network' (p. 551). He argues that the width of appropriation is essentially based on the investment by and the exchange of expertise of people who are more knowledgeable than others:

... they play a special role providing a range of information to those around them; they help others with their personal adoption of new technologies; they assist in interpreting what new technologies might mean for their lives and those around them; and they provide on-going practical support in the use of and upgrading of ICTs. (p. 551)

Similarly, Bakardjieva (2005) refers to 'warm experts' to pinpoint close-knit networked relations who have online proficiency and who are able to mediate '.. between the technological universal and the concrete situation, needs and background of the novice user 
with whom s/he is in a close personal relationship' (p. 99). Bakardjieva's research shows how people rely on multiple relatives or friends to guide the first steps on the Internet, share their own crystallized personal experiences, and help whenever something is unclear. Moreover, over time, her informants took up the role of warm expert themselves, helping less knowledgeable others. Moreover, even experienced users keep depending on warm experts, occasionally seeking 'warmer expertise' (Green et al., 2011).

Hence, social support is a key in learning about technology. In the social cognitive literature (Bandura, 1986, 1994), two types of learning are discerned: enactive learning (i.e. learn by the consequences of first-hand experience) and vicarious or observational learning (i.e. learn by observing and replicating physical or symbolic models). The latter type, provided by support networks (e.g. follow the examples and instructions by friends), is pinpointed as most powerful and efficient, as it provides immediate information about appropriate actions, reinforces efficacy expectations and hence influences motivation.

Support sources. Both Stewart (2007) and Bakardjieva (2005) stress the heterogeneity of support networks, although in the literature two domains surface: family support on the one hand (usually bound to the privacy of the home), and peer and workplace support on the other.

Chu (2010) emphasizes the twofold role of the family, providing tangible (i.e. instructions, shared and mediated use, and infrastructure) and emotional support (i.e. encouragement and persuasion). Family support appears to function inter-generationally and often bi-directional, underlining the importance of inter-generational transactions of knowledge and skills from children to parents (Correa et al., 2013) and grandchildren to grandparents (Barbosa-Neves et al., 2013). Likewise, parental mediation of children and teenagers' Internet use often occurs, albeit with seemingly limited effectiveness (Livingstone and Helsper, 2008). Still, learning from family is not always that evident, efficient nor preferential: family members might be unavailable, be reluctant and impatient to help or even refuse support. Such occurrences potentially provoke negative consequences in terms of efficacy beliefs and motivations. Evidently, peers with a similar background prove much more helpful (Lin et al., 2010).

The successful uptake of online technologies extends beyond the domestic environment. Importantly, the workplace is often the original site of acquaintance with technologies, where proficiency in handling them is considered a necessity (Garrido et al., 2012). This is paired with both positive and negative consequences, for example, increased motivation by improving communication and productivity, but also stress due to higher expectations and requirements (Day et al., 2010). Recent research (Day et al., 2012) shows that personal Information and Communication Technology (ICT) support (i.e. having a supportive and responsive ICT staff) negatively moderates the positive relationship between computer hassles and burnout symptoms such as strain and cynicism. Moreover, the availability of structural resource support (i.e. well-maintained up-to-date systems) attenuates the positive relation between the perceived expectations of having to learn at a fast pace and ICT stress.

This study expects heterogeneity in patterns of support sources. More specifically, drawing upon the aforementioned difference between enactive learning and vicarious learning, we expect to encounter a segment of self-reliant ICT learners (H4a), next to 
segments of vicarious learners. The latter, drawing upon social models, is expected to divide into at least two additional patterns: (H4b) a dominant presence of family (and friend) support on the one hand, and (H4c) personal workplace support on the other.

Subsequently, we hypothesize (H5) differences in social support, explained by sociodemographic variables that indicate pre-existing social and economic inequalities (e.g. social, ethnic and economic background; DiMaggio et al., 2004; Ono and Zavodny, 2007). Issues of digital inequalities have shown to be tied to socio-demographically and socio-economically underprivileged social milieus (i.e. 'offline inequalities'). If we take into account the concept of social homophily, referring to 'the principle that a contact between similar people occurs at a higher rate than among dissimilar people' (McPherson et al., 2001), it is plausible that digital inequalities are socially reproduced by the lack of adequate warm experts; that there is simply no one suitable willing to help.

Finally, we question how patterns of social support affect the relations between access quality, skills and motivation. More specifically, in H6, we hypothesize different types of social support to moderate these proposed direct and indirect effects (cf. H1-H3). Figure 1 schematically summarizes the study's hypotheses, whereas Table 1 offers a textual summary.

\section{Method}

\section{Procedure}

This study took place in Ghent, a Belgian city with a relatively young and ethnically diverse population of almost 250,000 (1565 inhabitants $\left./ \mathrm{km}^{2}\right)$. The city invests substantial resources in inclusion policies and its digital inequalities programme Digitaal. Talent@Gent.

The data collection was based on a stratified random sample of the population register, taking into account neighbourhood, gender, age category and national origin. Paper questionnaires were mailed to an initial wave of 2635 potential respondents, later on followed by a second wave of 705 to better meet census quota. A postal reminder was sent 1 week after the receipt of the initial invitation. This led to 850 valid responses. The dataset was then weighted post hoc, to ensure representativeness for respondents' gender, age category and nationality in accordance with census data (mean weight $=1.05$, standard deviation $[S D]=.28$ ). A total of $12 \%$ of the respondents indicated not to use the Internet; hence, they were omitted from the sample. As such, the final sample consists of 749 respondents with a mean age of 43.83 years $(S D=14.41), 51 \%$ of which are female. A majority of $70 \%$ has the Belgian nationality. A proportion of $39 \%$ has a secondary school degree, whereas $51 \%$ enjoyed college or university education. The average reported family size is $2.83(S D=1.34)$.

\section{Measures}

In accordance with the proposed conceptual model (Figure 1), the questionnaire contained operational measures of access quality, motivation, content-related skills, usage frequency and positive outcomes. Detailed descriptions of these measurement instruments are enumerated in the following paragraphs (item enumerations are included in Appendix 1). 


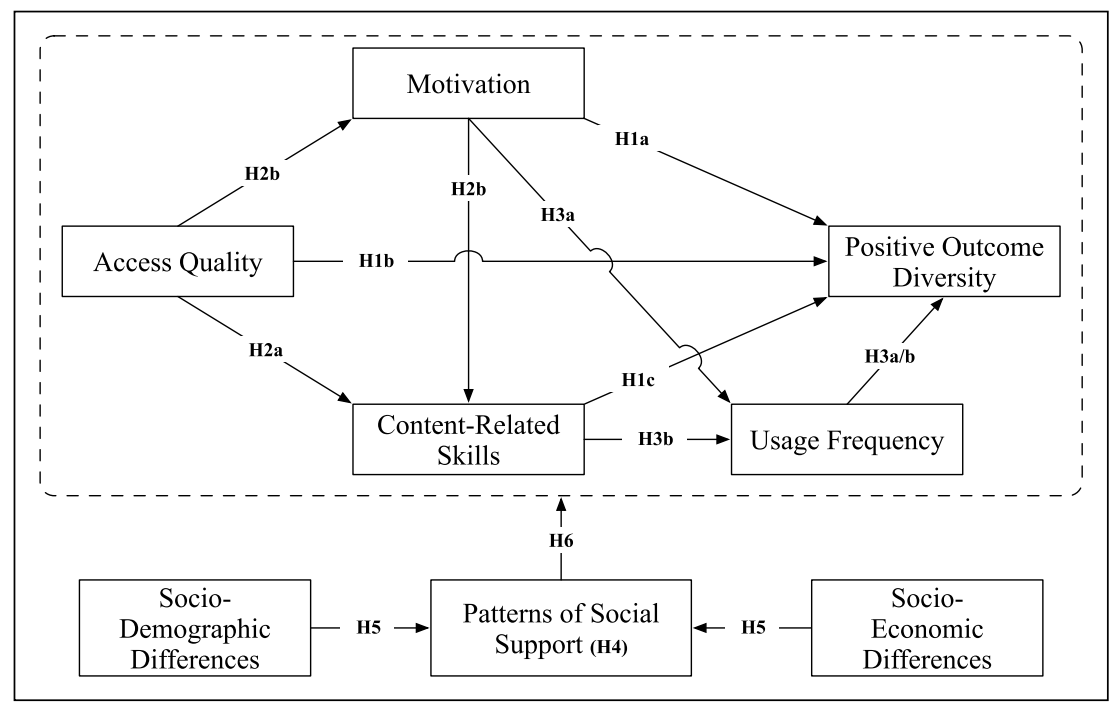

Figure I. Schematic presentation of the study's hypotheses.

Access quality was measured by the average sum of three 7-point Likert-items inquiring the ability to use a computer and the Internet in a desired environment $(M=6.11$, $S D=.99)$. The scale ranged from 'never' to 'always'. The measure's three items significantly load on a single component, explaining $78 \%$ of the initial variance. Furthermore, the scale demonstrates good internal consistency $(\alpha=.86)$.

Motivation was measured by averaged sum of a set of six expected outcomes drawn from socio-cognitive research on Internet attendance (see LaRose and Eastin, 2004; LaRose et al., 2001; Peters et al., 2006; $M=4.26, S D=1.14$ ). Each Likert-item represents a theoretically founded incentive category, as proposed by Bandura (1986; social, novel, activity, self-reactivity, status and monetary incentives). The instrument scale inquired the respondents' perception of the likelihood of obtaining such incentives by using the Internet. The scale ranged, inquiring this chance, from 'very small' to 'very large'. The measure's six items significantly load on a single component, explaining $50 \%$ of the initial variance. The scale also shows good internal consistency $(\alpha=.78)$.

Content-related skills were measured with a three-dimensional, frequency-based instrument adopted from Van Deursen et al. (2014; never to daily; 5-point scale), including information, communication and strategic skills $(\alpha=.70-.77)$. This particular extended version was originally based on a two-dimensional instrument (i.e. information and strategic skills) that previously demonstrated satisfactory psychometric properties (Van Deursen et al., 2014). For the sake of parsimony, these correlating dimensions were again subjected to a principal component analysis, which led to a single component, explaining $63 \%$ of the variance. Consequently, the variables were averaged in a secondorder measure of content-related skills $(M=2.93, S D=1.28)$.

Usage frequency was measured by asking respondents to indicate how many hours they would use the Internet on a normal weekday (Monday-Friday) and weekend day 
(Saturday-Sunday). Before analysis, this was recoded to a weighted weekly measure $(M=23.71, S D=23.40)$.

Positive outcome diversity was measured by 10 dichotomous items inspired by previous studies (Colley and Maltby, 2008; Selwyn et al., 2005; Van Deursen et al., 2014), inquiring whether respondents previously experienced various important outcomes as a consequence of Internet usage (e.g. finding a job, handling paperwork, join an organization like a sports club, cultural organization, a labour union or political organization $[M=4.02, S D=2.05]$; see Appendix 1 for a full enumeration and distribution). These dichotomous measures were then summed into a single variable, ranging from 0 to 10 .

Received and preferred help were each independently measured by five dichotomous items, inquiring whether various people (i.e. family to strangers) (a) are actually called upon for help with computer and Internet issues and (b) are preferred to offer support (i.e. who is considered an ideal source of support). This distinction is made because, as argued, the source of help on uses not necessarily conforms to his or her desire due to unavailability, quality of support, or even refusal (Lin et al., 2010). In order to identify such discrepancies, 'received help' and 'preferred help' were compared per potential source and recoded into a single four-level discrepancy measure. As such, we identified (a) help received from a non-preferred source $(1,0)$, (b) no need for help $(0,0)$, (c) no received help, despite clear preference $(0,1)$, and (d) the ideal and most gratifying situation of getting help from a preferred source $(1,1)$. These measures were supplemented by additional descriptive questions, equally enumerated in Appendix 1 (see Table 4 for more details on the measures' levels).

Socio-demographics, also included in the questionnaire, consist of age, gender, family size, education, employment, health condition, financial condition and ethnic background (see Table 6 for more details on the measures' levels).

\section{Results}

\section{Initial model testing}

The first three hypotheses $(\mathrm{H} 1-\mathrm{H} 3)$ in this study concern the validation of the proposed operational digital inequalities model. A path model was computed, based on a weighted covariance matrix of the entire sample of Internet users. This model demonstrates both absolute and relative goodness-of-fit $\left(\chi^{2}(1)=.47, p=.50\right.$, Tucker-Lewis Index $[\mathrm{TLI}]=1.00$, comparative fit index $[\mathrm{CFI}]=1.00$; root mean square error of approximation $[$ RMSEA] $=.00, p$ close $=.74$, standardized root mean square residual $[\mathrm{RMR}]=.007$; Figure 2).

The analysis focuses on indirect and total effects, as summarized in Table 2. It shows that in the tested model, motivation and skills have strong total effects on the diversity in positive outcomes $(\mathrm{H} 1 \mathrm{a} / \mathrm{c})$, jointly explaining $33 \%$ of its variance. Direct effects of motivation and skills mainly account for these total effects. Nevertheless, there is a moderate indirect effect of motivation. This is due to mediation by skills, as usage frequency has a null effect on positive outcome diversity. This implies that the outcomes of Internet usage are not contingent with how much it is used $(\mathrm{H} 3 \mathrm{a} / \mathrm{b})$. Although access quality has a marginal, yet significant effect on motivation, there is no sign of a significant direct 


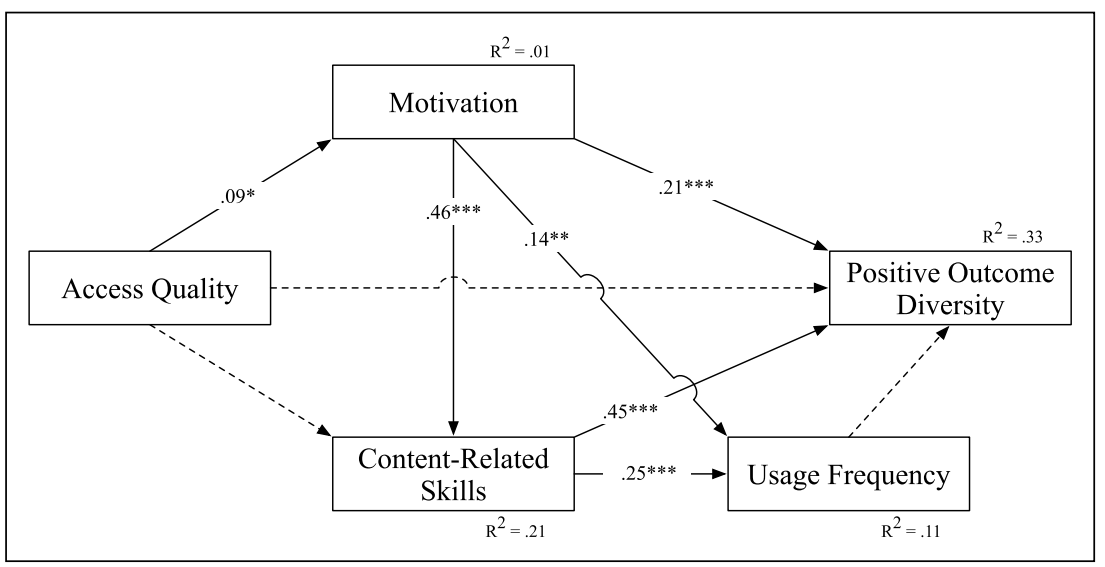

Figure 2. Digital inequalities model fit on the global sample. $*_{p}<.05, * * p<.005$ and $*^{* * *} p<.001$.

Table 2. Direct, indirect and total effects of access quality, skills and motivation on the diversity of positive outcomes.

\begin{tabular}{llllll}
\hline & & & Direct effects $\beta$ & Indirect effects $\beta$ & Total effects $\beta$ \\
\hline Access quality & $\rightarrow$ & Positive outcomes & .02 & .03 & .05 \\
Skills & $\rightarrow$ & Positive outcomes & $.21^{* * *}$ & .00 & $.45^{* * * *}$ \\
Motivation & $\rightarrow$ & Positive outcomes & $.45^{* * *}$ & $.20^{* * * *}$ & $.41^{* * *}$ \\
\hline
\end{tabular}

$* * * p<.001$.

(H1b) or indirect effect on the diversity of outcomes. Neither is there a direct effect of access quality on skills (H2a), although we notice a minimal indirect effect, through positive mediation by motivation $(\mathrm{H} 2 \mathrm{~b}, \beta=.04, p<.05)$.

\section{Latent class analysis}

The fourth hypothesis $(\mathrm{H} 4 \mathrm{a}-\mathrm{c})$ predicted distinguishable patterns within help obtained and preferential sources of help. In order to empirically verify this supposed multiplicity, we employed a model-based clustering technique (i.e. latent class analysis [LCA]). This technique allows uncovering latent structures in multivariate non-parametric data. Rather than artificially juxtaposing categories, this analysis allows grasping the complexities and interactions in combining various sources of support. More specifically, seven indicator variables are included in the analysis: five measures of discrepancies in requested and preferred help, one measure of what to do in case of a problem, and a measure of having someone available to provide help.

Typically when performing an LCA, a series of models are computed with an increasing number of classes. The most parsimonious well-fitting model is retained for further 
Table 3. Latent class analysis results, summarizing the iterative model comparisons with the third model as the first to attain a satisfactory model fit.

\begin{tabular}{|c|c|c|c|c|c|c|c|c|}
\hline$N$ clusters & LL & $\mathrm{BIC}$ & $\mathrm{AIC3}$ & $N$ parameters & $L^{2}$ & $d f$ & $p$ & $\begin{array}{l}\text { Classification } \\
\text { error }\end{array}$ \\
\hline I & -3925.70 & 7970.66 & 7669.53 & 18 & 1080.40 & 736 & .000 & .00 \\
\hline 2 & -3832.62 & 7910.39 & 7970.66 & 37 & 894.24 & 717 & .000 & .12 \\
\hline 3 & -3750.77 & 7872.58 & 7910.39 & 56 & 730.54 & 698 & .190 & .14 \\
\hline 4 & -3723.21 & 7943.36 & 7943.12 & 75 & 675.42 & 679 & .530 & .18 \\
\hline
\end{tabular}

BIC: Bayesian information criterion, LL: Log-likelihood, AIC: Akaike information criterion.

analysis. In this case, a three-class model is the first to attain a non-significant $L^{2}$ measure, which is a badness-of-fit index. Moreover, it has the smallest Bayesian information criterion (BIC) and AIC3 values, which are common measures for model comparisons. The model summaries are enumerated in Table 3.

The three-class model reveals quite delineated profiles. The response probabilities per indicator variable per class are included in Table 4 . The first profile $(62 \%)$, henceforward referred to as domestically networked (needing help), consists of Internet users who often rely on others to help out with a problem $(p=.84)$, especially family members, and friends in second instance. Hence, this profile reflects the hypothesized segment that predominantly draws upon family support (H4a). There is little need for assistance beyond the closest network. The second profile (25\%) consists of Internet users who often tend to ask for help $(p=.62)$. Although the family too is a refuge for assistance, there is a much higher probability of asking friends and colleagues. This class is labelled non-domestically networked (needing help), as they seek assistance beyond the domestic sphere. The finding of this segment supports H4c. Moreover, there are quite considerable probabilities of considering help from significant others as not ideal (get the help, but it is not by the preferred source), perhaps even inadequate $(p=.19-.33)$. The third and final class $(13 \%)$ is referred to as self-reliants. They seldom ask for help, usually solving problems on their own $(p=.80)$. They demonstrate high chances of not needing any help. Finding this final, smaller segment supports $\mathrm{H} 4 \mathrm{a}$.

Further analysis (Table 5) points out that the levels of digital divide factors (i.e. access quality, motivation, content-related skills) are unequally spread over the support source patterns, as well as in their consequences (i.e. usage frequency and positive outcome diversity). This seems to be marginally the case for motivation, whereas access quality is equal among patterns. A large difference is found within usage frequency, and especially skills, in which the domestically networked report a relatively low mean level. This is also reflected in the diversity of positive outcome diversity.

The study's fifth hypothesis proposed a shimmering through of existing inequalities in socio-demographic and socio-economic terms in the availability of support networks. It was hypothesized that disadvantaged milieus have difficulties to find gratifying support within their social networks. Three regression models were with the probability of latent cluster membership as a dependent variable (Table 6). In other words, models were 
Table 4. Response probabilities for all seven indicator variables per class.

\begin{tabular}{|c|c|c|c|c|c|}
\hline & $\begin{array}{l}\text { Domestically } \\
\text { networked }\end{array}$ & $\begin{array}{l}\text { Non- } \\
\text { domestically } \\
\text { networked }\end{array}$ & $\begin{array}{l}\text { Self- } \\
\text { reliants }\end{array}$ & Wald & $R^{2}$ \\
\hline Cluster size & .62 & .25 & .13 & & \\
\hline \multicolumn{4}{|c|}{ When I have a computer/Internet problem } & $55.72 * * *$ & .25 \\
\hline I am left with it & .01 & .03 & .10 & & \\
\hline I sometimes ask for help & .84 & .62 & .10 & & \\
\hline I solve it on my own & .14 & .36 & .80 & & \\
\hline Have no one to help & .00 & .00 & .14 & .93 & .12 \\
\hline \multicolumn{4}{|l|}{ Discrepancy help from family members } & $55.04 * * *$ & .22 \\
\hline No help, despite preference & .05 & .00 & .08 & & \\
\hline Help from preferred source & .75 & .53 & .01 & & \\
\hline Help from non-preferred source & .03 & .33 & .11 & & \\
\hline No need for help & .18 & .14 & .80 & & \\
\hline \multicolumn{4}{|l|}{ Discrepancy help from friends } & $12.11 *$ & .09 \\
\hline No help, despite preference & .06 & .00 & .13 & & \\
\hline Help from preferred source & .48 & .81 & .27 & & \\
\hline Help from non-preferred source & .11 & .19 & .14 & & \\
\hline No need for help & .34 & .00 & .46 & & \\
\hline \multicolumn{4}{|l|}{ Discrepancy help from colleagues } & $30 * * *$ & .17 \\
\hline No help, despite preference & .04 & .02 & .10 & & \\
\hline Help from preferred source & .28 & .73 & .19 & & \\
\hline Help from non-preferred source & .06 & .16 & .03 & & \\
\hline No need for help & .62 & .08 & .68 & & \\
\hline \multicolumn{4}{|c|}{ Discrepancy help from stranger on the Internet } & $43.64 * * *$ & .14 \\
\hline No help, despite preference & .02 & .02 & .10 & & \\
\hline Help from preferred source & .00 & .18 & .14 & & \\
\hline Help from non-preferred source & .01 & .19 & .04 & & \\
\hline No need for help & .97 & .61 & .72 & & \\
\hline \multicolumn{4}{|l|}{ Discrepancy help from a course teacher } & 10.90 & .02 \\
\hline No help, despite preference & .01 & .00 & .01 & & \\
\hline Help from preferred source & .04 & .07 & .03 & & \\
\hline Help from non-preferred source & .10 & .21 & .16 & & \\
\hline No need for help & .85 & .72 & .80 & & \\
\hline
\end{tabular}

$*_{p}<.05$ and $* * * k p<.001$.

built to explain what socio-demographic and socio-economic variables explain a particular pattern of support seeking.

The results indicate that soliciting the domestically networked (needing help) support pattern, reflecting a generally gratifying support from family members in first and friends in second instance, is explained by being female, older in age, part of a somewhat larger family, unemployed and having the tendency to use the Dutch language on the Internet. 
Table 5. Analysis of variance with support source patterns as fixed factor and the model variables as dependent variables.

\begin{tabular}{|c|c|c|c|c|c|c|c|}
\hline & \multicolumn{2}{|c|}{$\begin{array}{l}\text { Domestically } \\
\text { networked, } \\
\text { needing help }\end{array}$} & \multicolumn{2}{|c|}{$\begin{array}{l}\text { Non-domestically } \\
\text { networked, needing } \\
\text { help }\end{array}$} & \multicolumn{2}{|c|}{ Self-reliants } & \multirow[t]{2}{*}{$F(2,705)$} \\
\hline & $M$ & $S D$ & $M$ & $S D$ & $M$ & $S D$ & \\
\hline Access quality & 6.12 & 1.02 & 6.16 & .85 & 6.02 & 1.06 & .60 \\
\hline Motivation & 4.19 & 1.17 & 4.49 & 1.02 & 4.22 & 1.11 & $4.58^{*}$ \\
\hline Content-related skills & 2.78 & 1.31 & 3.52 & 1.04 & 3.33 & 1.11 & $24.84 * * *$ \\
\hline Usage frequency & 3.07 & 3.32 & 3.87 & 3.27 & 4.05 & 3.38 & $6.10 * *$ \\
\hline $\begin{array}{l}\text { Positive outcome } \\
\text { diversity }\end{array}$ & 3.60 & 1.99 & 4.96 & 1.96 & 4.36 & 1.88 & $31.09 * * *$ \\
\hline
\end{tabular}

SD: standard deviation.

$* p<.05, * * p<.005$ and $* * * p<.001$.

Table 6. Multiple linear regression models per cluster, employing continuous cluster membership probability between 0 and $I$ as a dependent variable and socio-economic and socio-demographic variables as independents.

\begin{tabular}{|c|c|c|c|}
\hline & $\begin{array}{l}\text { Domestically } \\
\text { networked, } \\
\text { needing help }\end{array}$ & $\begin{array}{l}\text { Non-domestically } \\
\text { networked, needing } \\
\text { help }\end{array}$ & Self- reliants \\
\hline Gender ( 0 = female, $I=$ male $)$ & $-.22 * * *$ & $.16 * * *$ & $.11 * *$ \\
\hline Age & $.24 * * *$ & $-.22 * * *$ & -.07 \\
\hline $\begin{array}{l}\text { Perceived financial situation (very } \\
\text { comfortable to very hard) }\end{array}$ & .06 & $-.10 *$ & .04 \\
\hline Family size & $.11 * * *$ & $-.07 *$ & -.06 \\
\hline $\begin{array}{l}\text { Born in Belgium ( } 0=\text { no, } \mathrm{I}=\text { yes) } \\
\text { Education (no to primary } \\
\text { education = reference) }\end{array}$ & .07 & -.06 & -.02 \\
\hline Education secondary & -.01 & .04 & -.03 \\
\hline Education college/university & $-.14^{*}$ & $.18^{* *}$ & -.02 \\
\hline Employment $(0=$ no, $\mathrm{I}=$ yes $)$ & $-.13 * * *$ & $.10^{*}$ & .06 \\
\hline $\begin{array}{l}\text { Language use during leisure (always } \\
\text { Dutch to always other language) }\end{array}$ & .07 & .02 & $-.12 *$ \\
\hline $\begin{array}{l}\text { Language use on the Internet (always } \\
\text { Dutch to always other language) }\end{array}$ & $-.19 * * *$ & .06 & $.19 * * *$ \\
\hline $\begin{array}{l}\text { Restrained to very restrained due to } \\
\text { health condition }\end{array}$ & -.02 & -.03 & .06 \\
\hline$F(1 I, 697)$ & 21.89 & 13.66 & 4.40 \\
\hline$R^{2}$ & $26 \%$ & $18 \%$ & $7 \%$ \\
\hline
\end{tabular}

$*_{p}<.05, * * p<.005$ and $* * * p<.001$.

Membership of the non-domestically networked (needing help) support pattern, drawing on friends and colleagues, is explained by being male, younger in age, smaller family size, a more comfortable financial situation, having enjoyed a higher education and being employed. 
Finally, the self-reliant pattern is only marginally explained by socio-demographic and economic variables. It shows younger respondents with the tendency to use nonDutch language(s) online - despite talking Dutch during otherwise - are more likely to solve their own problems, hence not needing any help at all.

Hence, in sum, we find that the support seekers who turn to family and friends are explained by relatively disadvantaged social and economic position, while their motivation, and especially their skills' levels are among the lowest. Moreover, support seekers who turn to friends and colleagues (hence a professional context), explained by higher education and a better financial situation, demonstrate the highest levels of resources and benefits. We consider both findings supportive of the homophily hypothesis (H5), stating that social and economic inequalities are reproduced in social networks.

\section{Subsample comparisons}

The previous analyses verified the multiplicity of the social support structures. The study's sixth hypothesis challenges whether these structures moderate the internal coherence of the inequalities model. This was verified through a multi-group analysis. More specifically, each latent class is split into a subsample. Next, the initial model is run on all three subsamples, so to compare the magnitudes of the parameter estimates in the model. In practice, three weighted covariance matrices were computed, taking into account the initial weighing procedure (gender, age, nationality).

Evidently, this multi-group model again accomplishes a satisfactory goodness-of-fit $\left(\chi^{2}(3)=6.35, p=.10, \mathrm{TLI}=.92, \mathrm{CFI}=.99 ; \mathrm{RMSEA}=.04\right)$. Again, we focus on direct, indirect and total effects of all three basic components on the diversity of positive outcomes (Table 7). Access quality has no effect, except for a small indirect one in the nondomestically networked pattern. When it comes to content-related skills, we see much stronger effects. The strongest direct effect of skills is demonstrated by the self-reliants. It shows that these independent Internet users draw upon their advanced skills to obtain positive outcomes. Interestingly, they display a negative effect of attendance on the diversity in outcomes, when controlled for skills. This implies that the variance in outcome diversity that is not explained by skills is negatively associated with the amount of time spent online. In other words, for this group, more time spent online that is not accounted for by skills is tied to a less rich Internet use. The other two patterns, which do turn to social support, have less strong direct effects of skills. However, when we look into the role of motivation, we see that the support patterns demonstrate relatively strong direct effects in explaining diverse positive outcomes, whereas the self-reliants display null effects. Nevertheless, they show the strongest indirect effect, whereas the socially supported respondents show weaker associations.

The outcomes of the study's hypotheses are summarized in Table 8.

\section{Discussion}

In this study, we have found that all three digital resources, which can be considered as mediators between offline and online fields of inclusion (i.e. access, skills and motivations; Helsper, 2012), continue to matter in explaining digital inequalities, either directly 


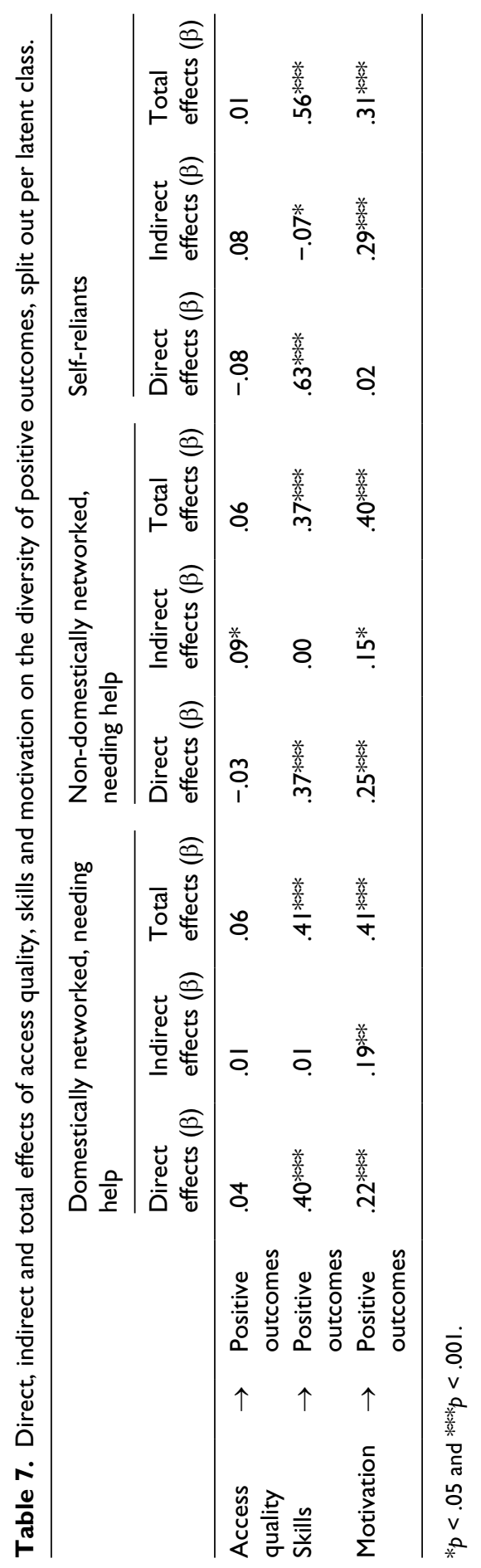


Table 8. Overview of the study's hypotheses and their evidence.

\begin{tabular}{|c|c|c|}
\hline \multicolumn{2}{|c|}{ Hypothesis } & \multirow{2}{*}{$\begin{array}{l}\text { Evidence } \\
\text { No }\end{array}$} \\
\hline $\mathrm{HIa}$ & $\begin{array}{l}\text { There is a direct effect of access quality on the diversity in positive } \\
\text { outcomes }\end{array}$ & \\
\hline HIb & $\begin{array}{l}\text { There is a direct effect of motivation on the diversity in positive } \\
\text { outcomes }\end{array}$ & Yes \\
\hline $\mathrm{HIC}$ & There is a direct effect of skills on the diversity in positive outcomes & Yes \\
\hline $\mathrm{H} 2 \mathrm{a}$ & There is a direct effect of access quality on skills & Yes \\
\hline $\mathrm{H} 2 \mathrm{~b}$ & The direct effect of access quality on skills is mediated by motivation & Yes \\
\hline $\mathrm{H} 3 \mathrm{a}$ & $\begin{array}{l}\text { The direct effect of motivation on the diversity in positive outcomes } \\
\text { is not mediated by usage frequency }\end{array}$ & Yes \\
\hline $\mathrm{H} 3 \mathrm{~b}$ & $\begin{array}{l}\text { The direct effect of skills on the diversity in positive outcomes is } \\
\text { not mediated by usage frequency }\end{array}$ & Yes \\
\hline $\mathrm{H} 4 \mathrm{a}$ & $\begin{array}{l}\text { Social support consists of a substantial proportion of self-reliant, } \\
\text { enactive learners }\end{array}$ & Yes \\
\hline $\mathrm{H} 4 \mathrm{~b}$ & $\begin{array}{l}\text { Social support consists of a substantial proportion of vicarious } \\
\text { learners, drawing upon family support }\end{array}$ & Yes \\
\hline $\mathrm{H} 4 \mathrm{c}$ & $\begin{array}{l}\text { Social support consists of a substantial proportion of vicarious } \\
\text { learners, drawing upon workplace support }\end{array}$ & Yes \\
\hline H5 & $\begin{array}{l}\text { These differences in social support are explained by socio- } \\
\text { demographic variables, indicating pre-existing social and economic } \\
\text { inequalities }\end{array}$ & Yes \\
\hline $\mathrm{H} 6$ & $\begin{array}{l}\text { These differences in social support moderate the direct and indirect } \\
\text { effects posited in } \mathrm{HI}-\mathrm{H} 3\end{array}$ & Yes \\
\hline
\end{tabular}

or indirectly. Although access quality does not explain the diversity in positive outcomes, it does affect the motivation that supports attaining them. In fact, we encountered a full mediation of the relation between access quality and skills on content-related skills by motivation. Still, as hypothesized, motivation and content-based Internet skills appear focal factors. Both share strong, independent direct associations with positive outcomes, while skills' level functions as a partial mediator of motivation. This hints to a complex interplay between motivation and the acquisition of skills, both functioning as the substrate for an effective Internet use. Still, some caution is required in interpreting the diversity of positive outcomes. A variety of domains (social, economic, etc.) tend to favour the younger and employed population, which needs to be taken into account.

Most important though is our finding of three patterns of support sources. In our sample, we encountered a dominant pattern of soliciting and receiving help from family members in first and friends in second instance. This indicates that a strong social embeddedness is a key factor in getting the necessary support. Still, it is sobering to encounter that this pattern is the least motivated, and especially has the lowest level of content-related skills. Moreover, this is reflected in the diversity of positive outcomes that are attained. When we took into account the social and economic background of this pattern, we found that the probability of belonging to this pattern is predominantly explained by gender, higher age, being part of a minority, family size and presumably linguistic ability. This incites to wonder whether the quality of support suffices. Taking into account the notion of homophily, 
it is plausible that in these social networks, warm experts (if any) themselves lack sufficient skills. In that case, help might be readily available, but not of sufficient quality to help cross the so-called online usage gap, which is known to be associated with a knowledge gap (Bonfadelli, 2002; Van Dijk, 2005; Zillien and Hargittai, 2009).

This explanation is further corroborated by the second social support pattern we encountered. In this pattern, comprising a quarter of the sample, help is predominantly delivered from friends and colleagues. Unlike the domestically oriented support, these users demonstrate relatively high levels of motivation and skills, paired with the highest mean level of positive outcomes. This suggests that despite high levels of attachment and proficiency, help is still requested and moulded into online practices. A look into the social background of this pattern's members has showed us a predominance of males, younger age, higher education and a comfortable financial situation. Moreover, there are trends towards smaller family size and being part of an ethnic minority. Hence, we are dealing with a specific segment of high-status young professionals that relies on (professional) peers. Again, as proposed by the homophily thesis (McPherson et al., 2001), this hints towards an amplification of personal online resources by one's social network.

Users who do not require any help compose the third, yet marginal pattern. This seems legitimate, as they are indeed high in motivation and skills. Moreover, as Matzat and Sadowski (2012) demonstrated, skills can indeed be developed by self-instruction, especially for those who are already highly skilled. Membership to this pattern is hardly explained by the verified social position, as personal factors such as gender and mastering another language - presumably English - are mild explanatory variables.

Still, we are able to conclude that the majority of Internet users in our sample express the need for help, and to a reasonable extent receive that help. However, our findings suggest that the efficiency of such help is questionable, as it appears that they tend to reproduce inequalities.

Finally, we found that the usage of social support sources moderates the direct and indirect association between inequality sources (i.e. access quality, skills and motivation) and the diversity in positive outcomes. As expected, self-reliants mostly rely on their welldeveloped set of skills, indirectly supported by motivation. The support-seeking respondents, however, relatively tend to rely less on skill diversity and more on motivation. This could be explained by the influence of an available social network that continuously encourages actively using the Internet, demonstrating what is possible and what can be obtained by using it. Considering that in the domestically networked, motivation is generally low, the absence of warm experts' motivational support might cause dropping out.

In conclusion, this article clearly demonstrates the continuous relevance of social support. It shows an apparent link between both offline and online resources; it is an instance of how both offline and online inclusion go hand in hand (Helsper, 2012). Although the Internet is commonplace in today's contemporary society, and most of us have gained considerable experience in using it, we still tend to seek support from our social networks. However, these networks likely differ in their social location, which might affect the possibility to offer the needed support.

Importantly, this study relies on a random, stratified sample in a moderately urbanized context. Although this is of course an asset, it equally invites caution concerning its generalizability when it comes to more rural or metropolitan areas. Still, our findings correspond 
with previous studies, and thus amplify the possibility of conceptual generalization of the importance of social support. Research into digital inequalities, especially their social substrates, remains a focal point of attention for Internet researchers, especially considering their far-reaching consequences. However, we encourage going beyond individualized accounts of support seeking. More specifically, we urge further research to explore these social networks and identify warm experts, their skills' levels and ways of offering support, which allows understanding its social dynamics.

\section{Funding}

This research received no specific grant from any funding agency in the public, commercial or not-for-profit sectors.

\section{References}

Bakardjieva M (2005) Internet Society: The Internet in Everyday Life. London: SAGE.

Bandura A (1986) Social Foundations of Thought and Action. Englewood Cliffs, NJ: Prentice Hall.

Bandura A (1994) Self-Efficacy: The Exercise of Control. New York: Freeman.

Barbosa-Neves B, Amaro F and Fonseca JRS (2013) Coming of (Old) age in the digital age: ICT usage and non-usage among older adults. Sociological Research Online 18. Available at: http://www.socresonline.org.uk/18/2/6.html

Barzilai-Nahon K (2006) Gaps and bits: conceptual measurements for digital divide/s. Information Society 22: 267-278.

Bonfadelli H (2002) The Internet and knowledge gaps: a theoretical and empirical investigation. European Journal of Communication 17: 65-84.

Chu RJC (2010) How family support and Internet self-efficacy influence the effects of e-learning among higher aged adults - analyses of gender and age differences. Computers \& Education 55: 255-264.

Colley A and Maltby J (2008) Impact of the Internet on our lives: male and female personal perspectives. Computers in Human Behavior 24: 2005-2013.

Correa T, Straubhaar D, Chen W, et al. (2013) Brokering new technologies: the role of children in their parents' usage of the Internet. New Media \& Society. Epub ahead of print 15 October. DOI: $10.1177 / 1461444813506975$.

Day A, Paquet S, Scott N, et al. (2012) Perceived information and communication technology (ICT) demands on employee outcomes: the moderating effect of organizational ICT support. Journal of Occupational Health Psychology 17: 473-491.

Day A, Scott N and Kelloway EK (2010) Information and communication technology: implications for job stress and employee well-being. In: Perree P and Ganster D (eds) New Developments in Theoretical and Conceptual Approaches in Job Stress: Research in Occupational Stress and Well Being. Bingley: Emerald Group Publishing, pp. 317-350.

DiMaggio P, Hargittai E, Celeste C, et al. (2004) Digital inequality: from unequal access to differentiated use. In: Neckerman K (ed.) Social Inequality. New York: Russell Sage Foundation, pp. 355-400.

Eastin M and LaRose R (2000) Internet self-efficacy and the psychology of the digital divide. Journal of Computer-Mediated Communication 6. DOI: 10.1111/j.1083-6101.2000. tb00110.x.

Garrido M, Sullivan J and Gordon A (2012) Understanding the links between ICT skills training and employability: an analytical framework. Information Technologies \& International Development 8: 17-32. 
Green E, Singleton C and Davies P (2011) Sustaining digital inclusion in everyday life. Symposium, 'A Decade in Internet Time', Oxford University, Oxford, 21-24 September.

Hampton KN, Sessions L and Her E (2011) Core networks, social isolation, and new media. How Internet and mobile phone use is related to network size and diversity. Information, Communication \& Society 14: 130-155.

Hargittai E (2002) Second-level digital divide: differences in people's online skills. First Monday 7. Available at: http://firstmonday.org/article/view/942/864

Hargittai E (2010) Digital na(t)ives? Variation in Internet skills and uses among members of the 'Net Generation'. Sociological Inquiry 80: 92-113.

Hargittai E and Hinnant A (2008) Digital inequality. Differences in young adults' use of the Internet. Communication Research 35: 602-621.

Hassani SN (2006) Locating digital divides at home, work, and everywhere else. Poetics 34: 250 272.

Helsper EJ (2012) A corresponding fields model for the links between social and digital exclusion. Communication Theory 22: 403-426.

LaRose R and Eastin M (2004) A social cognitive theory of Internet uses and gratifications: toward a new model of media attendance. Journal of Broadcasting \& Electronic Media 48: 358-377.

LaRose R, Mastro D and Eastin M (2001) Understanding Internet usage: a social-cognitive approach to uses and gratifications. Social Science Computer Review 19: 395-413.

Lin CIC, Tang W-H and Kuo F-Y (2010) 'Mommy Wants to Learn the Computer': how middle-aged and elderly women in Taiwan learn ICT through social support. Adult Education Quarterly 62: 73-90.

Livingstone S and Helsper EJ (2007) Gradations in digital inclusion: children, young people and the digital divide. New Media \& Society 9: 671-696.

Livingstone S and Helsper EJ (2008) Parental mediation and children's Internet use. Journal of Broadcasting \& Electronic Media 52: 581-599.

McPherson M, Smith-Lovin L and Cook JM (2001) Birds of a feather: homophily in social networks. Annual Review of Sociology 27: 415-444.

Matzat U and Sadowski B (2012) Does the 'Do-It-Yourself approach' reduce digital inequality? Evidence of self-learning of digital skills. Information Society 28: 1-12.

Min S-J (2010) From the digital divide to the democratic divide: Internet skills, political interest, and the second-level digital divide in political Internet use. Journal of Information Technology \& Policy 7: 22-35.

Norris P (2001) Digital Divide, Civic Engagement, Information Poverty and the Internet Worldwide. Cambridge, MA: Cambridge University Press.

Ono H and Zavodny M (2007) Digital inequality: a five country comparison using microdata. Social Science Research 36: 1135-1155.

Peter J and Valkenburg P (2006) Adolescents' Internet use: testing the 'disappearing digital divide' versus the 'emerging digital differentiation' approach. Poetics 34: 293-305.

Peters O, Rickes M, Jöckel S, et al. (2006) Explaining and analyzing audiences: a social cognitive approach to selectivity and media use. Communications 31: 279-308.

Selwyn N (2004) Reconsidering political and popular understandings of the digital divide. New Media \& Society 6: 341-362.

Selwyn N, Gorard S and Furlong J (2005) Whose Internet is it anyway? Exploring adults' (non)use of the Internet in everyday life. European Journal of Communication 20: 5-26.

Stewart J (2007) Local experts in the domestication of information and communication technologies. Information, Communication \& Society 10: 547-569.

Van Deursen A and Van Dijk J (2010) Internet skills and the digital divide. New Media \& Society 13: 893-911. 
Van Deursen A, Courtois C and van Dijk J (2014) Internet skills, sources of support, and benefiting from internet use. International Journal of Human-computer Interaction 30(4): 278-290.

Van Deursen A, Van Dijk J and Peters O (2011) Rethinking Internet skills: the contribution of gender, age, education, Internet experience, and hours online to medium- and content-related Internet skills. Poetics 39: 125-144.

Van Dijk J (2005) The Deepening Divide Inequality in the Information Society. London: SAGE.

Van Dijk J (2006) Digital divide research, achievements and shortcomings. Poetics 34: 221-235.

Van Dijk J and Hacker K (2003) The digital divide as a complex and dynamic phenomenon. Information Society 19: 315-326.

Verdegem $P$ and Verhoest $\mathrm{P}$ (2009) Profiling the non-user: rethinking policy initiatives stimulating ICT acceptance. Telecommunications Policy 33(10-11): 642-652.

Warschauer M (2003) Technology and Social Inclusion: Rethinking the Digital Divide. Cambridge, MA: The MIT Press.

Wei L (2012) Numbers matters: the multimodality of Internet use as an indicator of the digital inequalities. Journal of Computer-Mediated Communication 17: 303-318.

Wei L and Hindman DB (2011) Does the digital divide matter more? Comparing the effects of new media and old media use on the education-based knowledge gap. Mass Communication and Society 14: 216-235.

Zillien N and Hargittai E (2009) Digital distinction: status-specific types of Internet usage. Social Science Quarterly 90: 274-291.

\section{Author biographies}

Cédric Courtois is an Assistant Professor in Media Sociology and Research Designs at the Faculty of Social Sciences, KU Leuven - Belgium. He is a member of the Leuven School for Mass Communication research. His research interests are in the appropriation of digital media and social change in the field social media in specific.

Pieter Verdegem is an Assistant Professor in New Media and Information and Communication Technologies (ICT) in the Department of Communication Sciences at Ghent University. He is also affiliated with the Research Group for Media \& ICT (iMinds-MICT). His research interests are in ICT and society, social media, political economy, new media and ICT policies and governance.

\section{Appendix I}

a. Access Quality

How often ...

- Can you use a computer when you want to?

- Can you access the Internet when you want to?

- Can you access the Internet in an agreeable environment?

(Never - Very seldom - Seldom - Sometimes - Often - Very often - Always)

\section{b. Expected Outcomes (Motivation)}

How likely is it that by using the Internet ... 
- You feel connected to others?

- You keep updated on all sorts of information?

- You have a good time?

- You spend your time well?

- You gain respect from others?

- You can get something advantageous?

(7-point scale, from Very unlikely-Very likely)

c. Content-Related Skills

How often:

\section{Information.}

- Do you use special operators such as + or "?

- Do you use more than one search keyword?

- Do you look beyond the first three search results?

- Do you cross-check information on other web sites?

- Do you evaluate whether the information you found is reliable?

Communication.

- Do you ask people for advice?

- You get positive reactions on an online profile?

- You make new contacts?

- You react on a message on an online forum?

- You get comments on something you posted?

(5-point scale, from Never-Daily)

d. Positive Outcomes

Through the Internet ...

- I found a job.

- I bought a cheaper product.

- I found out what political party to vote for.

- I found a club to joint (e.g. sports, cultural association, union, political organization).

- I made one or more friends I later on met in person.

- I found a potential partner.

- I found out what medical problem I had.

- I planned a trip.

- I handled paperwork faster (e.g. taxes, invoices).

- I had successful contact with government institutions.

(Yes or No) 